\title{
Post-transplant diabetes mellitus in pediatric liver transplantation
}

\author{
Hathout E, Alonso E, Anand R, Martz K, Imseis E, Johnston J, Lopez \\ $\mathrm{J}$, Chinnock R, McDiarmid S. Post-transplant diabetes mellitus in \\ pediatric liver transplantation. \\ Pediatr Transplantation 2009: 13:599-605. @ 2007 John Wiley \& Sons A/S.
}

Abstract: To determine the characteristics of pediatric liver transplant recipients who develop GI and/or PTDM, data on children undergoing their first liver transplant from the SPLIT database were analyzed $(\mathrm{n}=1611)$. Recipient and donor characteristics that were evaluated included age at transplant, gender, race, primary disease, hospitalization status at transplant, BMI, recipient and donor CMV status, donor type, donor age, and primary immunosuppression. GI/PTDM was found in 214 individuals $(13 \%)$ of whom $166(78 \%)$ were diagnosed within 30 days of transplantation (early GI/PTDM). Multivariate analyses suggests that age $>5 \mathrm{yr}$ at transplant, hospitalization at transplant, a primary diagnosis other than BA, early steroid use, and tacrolimus use are associated with increased incidence of early GI. Routine monitoring for the development of GI and post-transplant diabetes is indicated in the short- and long-term care of children after liver transplantation.

\author{
Eba Hathout', Estella Alonso², \\ Ravinder Anand ${ }^{3}$, Karen Martz ${ }^{3}$, \\ Essam Imseis ${ }^{4}$, Joyce Johnston ${ }^{1}$ \\ James Lopez ${ }^{5}$, Richard Chinnock ${ }^{1}$, and \\ Sue McDiarmid ${ }^{6}$ on behalf of the \\ SPLIT study group*
}

${ }^{1}$ Division of Pediatric Endocrinology and Diabetes, Loma Linda University, Loma Linda, CA, ${ }^{2}$ Division of Pediatric Gastroenterology, Northwestern University, Chicago, IL, ${ }^{3}$ EMMES, Rockville, MD, ${ }^{4}$ Division of Pediatric Gastroenterology, Ochsner Clinic

Foundation, New Orleans, LA, ${ }^{5}$ Division of Pediatric Gastroenterology, University of Michigan, Ann Arbor, $\mathrm{MI},{ }^{6}$ Division of Pediatric Gastroenterology, UCLA, Los Angeles, CA, USA

${ }^{*}$ See the Appendix for the SPLIT centers.

Key words: post-transplant diabetes - pediatrics liver transplantation - islets - immunosuppression

Eba Hathout, Chief, Division of Pediatric Endocrinology and Diabetes, Pediatric Diabetes Center \& Islet Transplant Laboratory, Department of Pediatrics, Loma Linda University School of Medicine, 11175 Campus Street, CP A1120R, Loma Linda, CA 92354, USA

Tel.: 9095584130

Fax: 9095580408

E-mail: ehathout@llu.edu

Accepted for publication 28 November 2007
The universal rise in incidence of pediatric diabetes (ranging from 5 to 40 cases per 100000 per year) has been paralleled by increasing recognition of post-transplant hyperglycemia as a unique form of iatrogenic diabetes. PTDM is an increasingly recognized complication of solid organ transplantation (1-3). Overall reported frequencies of PTDM in adults range from $4 \%$ to $40 \%$ (4), depending on the transplanted organ, definition of diabetes, and immunosuppressive

Abbreviations: ADA, American Diabetes Association; BA, biliary atresia; BMI, body mass index; CDC, Centers for Disease Control and Prevention; CMV, cytomegalovirus; GI, glucose intolerance; HLA, human leukocyte antigen; ICU, intensive care unit; PTDM, post-transplant diabetes mellitus; SPLIT, Studies of Pediatric Liver Transplantation. regimen (5). Risk factors for PTDM include tacrolimus use (6), age at transplant, obesity, family history of diabetes, pre- and post-transplant GI, ethnicity, and occasionally HLA sub-types (7). The long-term implications of pediatric PTDM, in terms of acceleration of known diabetic complications or development of new ones following decades of immune suppression remain to be discovered (8). Despite observed associations of PTDM with use of glucocorticoids (prednisone), tacrolimus (FK506), and less commonly, with cyclosporine (9), the relation of PTDM to various immunosuppressive medications has not been fully elucidated in the pediatric liver transplant population. The objectives of this study were to determine the frequency and characteristics of GI and PTDM in a large cohort of pediatric liver-transplant recipients. 


\section{Materials and methods}

The SPLIT database (10) is a prospective self-initiated center-reporting registry which was started in 1995 and now includes data from 3161 patients at 44 centers in the USA and Canada. The number of patients per center ranges from two to 283. This outcome analysis was based on data reported up to June of 2004 from 1611 patients who received their first liver only transplant while registered in one of the 39 participating SPLIT centers at the time of this analysis. Post-transplant follow-up forms are completed at 30 days, 6,12 , and 18 months and then annually following transplantation. Follow-up forms query use of insulin, other antihyperglycemic drugs or other evidence of diabetes or GI at any time point since the last follow-up. Plasma fasting glucose levels were not requested as part of the data collection and non-fasting blood glucose levels were inconsistently reported. Data regarding pre-existing diabetes prior to transplant were not collected. Therefore, for this analysis, patients were categorized as having GI or PTDM if they received insulin, antihyperglycemic drugs or were termed by their primary center as having diabetes or GI at any time point during post-transplant follow-up. Patients reported to have GI and or PTDM in the first 30 days post-transplant were considered to have developed early GI (PTDM). Data on diabetes-specific start or end dates were not collected to enable accurate estimation of diabetes duration. The study visit date at which GI/PTDM was first reported was used as the start date and end date was the last consecutive visit date at which diabetes was reported. The diabetes duration was set to 0 days when diabetes was not reported for more than one visit.

Patient and donor factors that were evaluated included age at transplant, gender, race, primary disease, hospitalization status at transplant, BMI at transplant, patient and donor CMV status, donor type, donor age, primary immunosuppression, steroid use, use of monoclonal and polyclonal antibodies, and year of transplant.

Fisher's Exact and chi-squared tests were used in the univariate analyses. Mulitvariate logistic regression analyses with backward elimination method was used to develop a risk factors model for early GI/PTDM.

\section{Results}

Table 1 provides a summary of patient characteristics at the time of transplant. One-third of the patients were $<1 \mathrm{yr}$ of age at the time of transplant and $34.7 \%$ were $>5 \mathrm{yr}$ of age at transplant. The median age at transplant is 1.93 yr. Forty-two percent of the patients were diagnosed with BA and fulminant liver failure patients accounted for $14.2 \%$ of the cohort. More than half of the patients $(56.7 \%)$ were not hospitalized at time of transplant. The standardized height was below age and gender adjusted mean for $80 \%$ of the patients and $>2$ s.d. below mean for more than a quarter of the patients. Unlike adults, BMI is age and gender specific for children. Normative data on BMI is available from CDC for children and young adults between the ages of 2 and $20 \mathrm{yr}$. CDC defines children with age and gender adjusted BMI in top $5 \%$ as being overweight and between 85 th
Table 1. Patient characteristics*

\begin{tabular}{|c|c|c|}
\hline \multirow[b]{2}{*}{ Total } & \multicolumn{2}{|l|}{ Total } \\
\hline & $n=1611$ & $\%$ \\
\hline \multicolumn{3}{|l|}{ Age at transplant (years) } \\
\hline $0-1$ & 540 & 33.5 \\
\hline $1-5$ & 510 & 31.7 \\
\hline $5-13$ & 334 & 20.7 \\
\hline $13+$ & 225 & 14.0 \\
\hline \multicolumn{3}{|l|}{ Sex } \\
\hline Male & 741 & 46.0 \\
\hline Female & 869 & 53.9 \\
\hline \multicolumn{3}{|l|}{ Race } \\
\hline White & 969 & 60.1 \\
\hline Black & 252 & 15.6 \\
\hline Hispanic & 237 & 14.7 \\
\hline Other & 150 & 9.3 \\
\hline \multicolumn{3}{|l|}{ Primary disease } \\
\hline Biliary atresia & 672 & 41.7 \\
\hline Other cholestatic & 220 & 13.7 \\
\hline Fulminant & 229 & 14.2 \\
\hline Metabolic & 208 & 12.9 \\
\hline Cirhosis & 122 & 7.6 \\
\hline Other & 158 & 9.8 \\
\hline \multicolumn{3}{|c|}{ Patient hospitalization at transplant } \\
\hline ICU & 432 & 26.8 \\
\hline Hospital/no ICU & 258 & 16.0 \\
\hline No hospital & 914 & 56.7 \\
\hline \multicolumn{3}{|l|}{ Steroid use at transplant } \\
\hline No & 152 & 9.4 \\
\hline Yes & 1459 & 90.6 \\
\hline \multicolumn{3}{|l|}{ Induction } \\
\hline No & 1392 & 86.4 \\
\hline Yes & 219 & 13.6 \\
\hline \multicolumn{3}{|l|}{ Immunosuppression use } \\
\hline CsA & 433 & 26.9 \\
\hline TAC & 931 & 57.8 \\
\hline Other/unknown & 247 & 15.3 \\
\hline \multicolumn{3}{|l|}{ BMI Z score $\dagger$} \\
\hline Above mean & 453 & 28.1 \\
\hline Within 1 s.d. below mean & 163 & 10.1 \\
\hline $1-2$ s.d. below mean & 58 & 3.6 \\
\hline$>2$ s.d. below mean & 26 & 1.6 \\
\hline \multicolumn{3}{|c|}{ Obesity status at $T x$ (using s.d. BMl for patients $\geq 2$ yr of age) } \\
\hline$<5$ th percentile & 43 & 6.1 \\
\hline 6-84th percentile & 437 & 62.4 \\
\hline 85-94th percentile & 132 & 18.9 \\
\hline$\geq 95$ th percentile & 88 & 12.6 \\
\hline \multicolumn{3}{|l|}{ Height $Z$ score } \\
\hline Above mean & 323 & 20.0 \\
\hline Within 1 s.d. below mean & 364 & 22.6 \\
\hline $1-2$ s.d. below mean & 402 & 25.0 \\
\hline >2 s.d. below mean & 412 & 25.6 \\
\hline \multicolumn{3}{|l|}{ Weight $Z$ score } \\
\hline Above mean & 478 & 29.7 \\
\hline Within 1 s.d. below mean & 354 & 22.0 \\
\hline$>2$ s.d. below mean & 332 & 20.6 \\
\hline >2 s.d. below mean & 417 & 25.9 \\
\hline \multicolumn{3}{|l|}{ Recipient CMV status } \\
\hline Negative/unknown & 1034 & 64.2 \\
\hline Positive & 577 & 35.8 \\
\hline \multicolumn{3}{|l|}{ Donor CMV status } \\
\hline Negative/unknown & 852 & 52.9 \\
\hline Positive & 759 & 47.1 \\
\hline
\end{tabular}


Post-transplant diabetes mellitus

Table 1. (Continued)

\begin{tabular}{lcr}
\hline & \multicolumn{2}{l}{ Total } \\
\cline { 2 - 3 } Total & $\mathrm{n}=1611$ & $\%$ \\
\hline Donor age (years) & & \\
0-1 & 137 & 8.5 \\
$1-18$ & 813 & 50.5 \\
18-50 & 567 & 35.2 \\
50+ & 57 & 3.5 \\
Donor organ type & & \\
Live & 267 & 16.6 \\
CAD whole & 813 & 50.5 \\
CAD reduced & 296 & 18.4 \\
CAD split & 174 & 10.8 \\
CAD organ not specified & 55 & 3.4 \\
Transplant year & & \\
1985-1999 & 815 & 50.6 \\
2000-2004 & 796 & 49.4 \\
\hline
\end{tabular}

ICU, intensive care unit; CMV, cytomegalovirus; CsA, cyclosporine; Tac, tacrolimus; $\mathrm{Tx}$, transplantation; BMI, body mass index; CAD, cadaveric.

* Missing data within a category are not shown.

†BMI Z score can be computed for patients' $\geq 2$ yr of age.

and 95th percentile as at risk for overweight. According to this definition, $12.6 \%$ of patients were overweight at transplant and another $18.9 \%$ were at risk for overweight at time of transplant. Thirty-six percent of recipients and $47.1 \%$ of donors were CMV positive at transplant. Seventeen percent of patients received an organ from a living donor and $29.2 \%$ received a cadaveric technical variant graft.

Table 2 describes early and late GI/PTDM event rates by patient characteristics at transplant. Of the 1611 patients receiving their first liver-only transplant, 214 (13.3\%) developed GI/ PTDM. The majority of patients developed GI/ PTDM within one month following transplantation $(166 / 214,77.6 \%)$. At subsequent follow-up visits, the number of children with a first report of GI/PTDM decreased sharply: 30 at month 6; five at month 12; four at month 18; four at month 24; two at month 36; two at month 48; and one at month 72 . The mean duration of GI/ PTDM for children diagnosed at one and six months $(\mathrm{n}=196)$ was 74.8 and 80.4 days, respectively.

As a result of staggered entry of patients in to the study leading to unequal follow-up posttransplant, all statistical comparisons focus on the development of GI/PTDM in the first month post-transplant (termed as early GI/PTDM). Overall, $10.3 \%$ of patients developed early GI/ PTDM. Children $>5 \mathrm{yr}$ of age were more likely to develop early GI/PTDM $(8.1 \%$ for age $<1 \mathrm{yr}$, $7.6 \%$ age $1-4 \mathrm{yr}, 12.0 \%$ age $5-12$ yr and $19.1 \%$ age $>12 \mathrm{yr} ;$ p-value $<0.0001)$. Children of
Table 2. Patient characteristics at transplant by GI/PTDM status

\begin{tabular}{|c|c|c|c|c|}
\hline Row \% & $\begin{array}{l}\text { Gl/PTDM } \\
<30 \\
\text { days } \\
n=166\end{array}$ & $\begin{array}{l}\text { Gl/PTDM } \\
>30 \\
\text { days } \\
n=48\end{array}$ & $\begin{array}{l}\text { No Gl/ } \\
\text { PTDM } \\
n=1397\end{array}$ & $\mathrm{p}$-value \\
\hline Total $(n=1611)$ & 10.3 & 3.0 & 86.7 & \\
\hline \multicolumn{5}{|l|}{$\begin{array}{l}\text { Age at transplant } \\
\text { (overall } p<0.0001 \text { ) }\end{array}$} \\
\hline$<1$ yr $(\mathrm{n}=540)$ & 8.1 & 0.9 & 90.9 & Reference \\
\hline $1-4$ yr $(n=510)$ & 7.6 & 1.4 & 91.0 & 0.7636 \\
\hline $5-12(n=334)$ & 12.0 & 5.1 & 82.9 & 0.0636 \\
\hline $13+$ yr $(n=225)$ & 19.1 & 8.4 & 72.4 & $<0.0001$ \\
\hline \multicolumn{5}{|l|}{ Gender (overall $p=0.95$ ) } \\
\hline Male $(n=741)$ & 10.3 & 3.0 & 86.8 & 0.95 \\
\hline Female $(n=869)$ & 10.4 & 3.0 & 86.7 & Reference \\
\hline \multicolumn{5}{|l|}{ Race (overall $p=0.0252$ ) } \\
\hline White $(\mathrm{n}=969)$ & 8.9 & 3.0 & 88.1 & Reference \\
\hline Black $(n=252)$ & 11.1 & 2.4 & 86.5 & 0.2781 \\
\hline Hispanic $(n=237)$ & 15.6 & 3.8 & 80.6 & 0.0024 \\
\hline Other $(n=150)$ & 10.0 & 2.0 & 88.0 & 0.6548 \\
\hline \multicolumn{5}{|l|}{$\begin{array}{l}\text { Primary disease } \\
\text { (overall } p=0.0037 \text { ) }\end{array}$} \\
\hline Biliary atresia $(n=672)$ & 6.7 & 2.2 & 91.1 & Reference \\
\hline $\begin{array}{l}\text { Other cholestatic } \\
(n=220)\end{array}$ & 13.6 & 4.5 & 81.8 & 0.0016 \\
\hline Fulminant $(n=229)$ & 11.4 & 2.2 & 86.5 & 0.0255 \\
\hline Metabolic $(n=208)$ & 13.0 & 3.8 & 83.2 & 0.0045 \\
\hline Cirrhosis $(n=122)$ & 15.6 & 4.9 & 79.5 & 0.0013 \\
\hline Other $(n=158)$ & 12.0 & 2.5 & 85.4 & 0.0259 \\
\hline \multicolumn{5}{|l|}{$\begin{array}{l}\text { Transplant year } \\
\text { (overall } p=0.5100 \text { ) }\end{array}$} \\
\hline 1995-1999 ( $n=815)$ & 10.8 & 3.8 & 85.4 & Reference \\
\hline $2000-2004(n=796)$ & 9.8 & 2.1 & 88.1 & 0.5100 \\
\hline
\end{tabular}

Gl, glucose intolerance; PTDM, post-transplant diabetes mellitus. p-value compares GI/PTDM within first 30 days vs. no GI/PTDM after first 30 days.

black or Hispanic race were more likely to develop early GI/PTDM compared to whites (11.1\% black, $15.6 \%$ Hispanic, and $8.9 \%$ white; $\mathrm{p}$-value 0.0252). Children diagnosed with BA had the lowest incidence of early GI/PTDM (6.7\%). This is consistent with the observation that children $<5 \mathrm{yr}$ of age at transplant had lower incidence of early GI/PTDM. It was interesting to note that there was no era effect on the development of early GI/PTDM $(10.8 \%$ before year 2000 and $9.8 \%$ between 2000 and 2004).

Table 3 describes the impact of clinical factors at transplant on the development of early GI/ PTDM. Sixteen percent of the children in ICU at transplant developed early GI/PTDM compared to $10.1 \%$ of those hospitalized at transplant and $7.9 \%$ for those non-hospitalized (p-value $<0.0001$ ). CMV negative patients had lower incidence of early GI/PTDM $(9.1 \%)$ compared to patients that were CMV positive at transplant $(12.5 \%$; p-value $=0.0326)$. The incidence of early GI/PTDM in children receiving a 
Table 3. Transplant clinical parameters by GI/PTDM status

\begin{tabular}{|c|c|c|c|c|}
\hline Row \% & $\begin{array}{l}\text { Gl/PTDM } \\
<30 \\
\text { days } \\
n=166\end{array}$ & $\begin{array}{l}\text { GI/PTDM } \\
>30 \\
\text { days } \\
n=48\end{array}$ & $\begin{array}{l}\text { No Gl/ } \\
\text { PTDM } \\
n=1397\end{array}$ & $\mathrm{p}$-value \\
\hline \multicolumn{5}{|l|}{$\begin{array}{l}\text { Patient status } \\
\text { (overall } p<0.0001 \text { ) }\end{array}$} \\
\hline ICU $(n=432)$ & 15.7 & 2.3 & 81.9 & $<0.0001$ \\
\hline $\begin{array}{l}\text { Hospital/no ICU } \\
(\mathrm{n}=258)\end{array}$ & 10.1 & 1.9 & 88.0 & 0.2608 \\
\hline $\begin{array}{l}\text { No hospitalization } \\
(\mathrm{n}=914)\end{array}$ & 7.9 & 3.6 & 88.5 & Reference \\
\hline \multicolumn{5}{|l|}{$\begin{array}{l}\text { BMI } Z \text { score } \\
\text { (overall } p=0.8020 \text { ) }\end{array}$} \\
\hline Above mean $(n=453)$ & 12.8 & 4.2 & 83.0 & Reference \\
\hline Below mean $(n=247)$ & 12.1 & 5.7 & 82.2 & 0.8020 \\
\hline \multicolumn{5}{|c|}{$\begin{array}{l}\text { Recipient CMV status } \\
\text { (overall } p=0.0326 \text { ) }\end{array}$} \\
\hline Positive ( $n=577)$ & 12.5 & 4.7 & 82.8 & 0.0326 \\
\hline $\begin{array}{l}\text { Negative/unknown } \\
(\mathrm{n}=1034)\end{array}$ & 9.1 & 2.0 & 88.9 & Reference \\
\hline \multicolumn{5}{|l|}{$\begin{array}{l}\text { Donor CMV status } \\
\text { (overall } p=0.2014 \text { ) }\end{array}$} \\
\hline Positive $(n=759)$ & 11.3 & 3.6 & 85.1 & 0.2014 \\
\hline $\begin{array}{l}\text { Negative/unknown } \\
(\mathrm{n}=852)\end{array}$ & 9.4 & 2.5 & 88.1 & Reference \\
\hline \multicolumn{5}{|l|}{$\begin{array}{l}\text { Donor type (overall } \\
p=0.0066 \text { ) }\end{array}$} \\
\hline Live $(n=267)$ & 5.6 & 1.9 & 92.5 & Reference \\
\hline Cadaver $(n=1338)$ & 11.3 & 3.2 & 85.5 & 0.0066 \\
\hline \multicolumn{5}{|l|}{$\begin{array}{l}\text { Donor age (overall } \\
p=0.5018 \text { ) }\end{array}$} \\
\hline$<18$ yr $(n=950)$ & 10.0 & 2.4 & 87.6 & Reference \\
\hline $18+$ yr $(n=624)$ & 11.1 & 4.0 & 84.9 & 0.5018 \\
\hline
\end{tabular}

GI, glucose intolerance; PTDM, post-transplant diabetes mellitus; ICU, intensive care unit; $\mathrm{BMI}$, body mass index; CMV, cytomegalovirus. p-value compares GI/PTDM within first 30 days vs. no GI/PTDM after first 30 days.

graft from a live donor is less than half of those receiving a cadaveric graft $(5.6 \%$ vs. $11.3 \%$, respectively; $\mathrm{p}$-value $=0.0066)$. Donor age and CMV status were not significant predictors of GI/PTDM in the univariate analyses. For children $>2$ yr of age the incidence of early GI/PTDM did not vary by standardized BMI score at the time of transplant.

Table 4 shows the incidence of early PTDM in BA patients. The data suggest that the incidence of early PTDM is higher among BA patients that were $>5 \mathrm{yr}$ of age at transplant $(9.8 \%$ vs. $6.3 \%)$, but the differences are not statistically significant. The majority of BA patients are $<5 \mathrm{yr}$ of age, however, the results of the multivariate analyses show that age is a significant predictor of diabetes after adjusting for other predictors including the primary diagnosis.

Tables 5 and 6 summarize the influence of primary immunosuppression on the development of early GI/PTDM. Fifty-eight percent of
Table 4. Incidence of diabetes in two age groups of patients with biliary atresia

\begin{tabular}{|c|c|c|c|c|c|}
\hline \multirow{2}{*}{$\begin{array}{l}\text { Biliary atresia } \\
\text { patients }(n=672)\end{array}$} & \multicolumn{2}{|c|}{$\begin{array}{l}\text { No PTDM } \\
\text { within } 30 \text { days }\end{array}$} & \multicolumn{2}{|c|}{$\begin{array}{l}\text { PTDM with- } \\
\text { in } 30 \text { days }\end{array}$} & \multirow{2}{*}{$\begin{array}{l}\text { Chi-square } \\
\text { p-value }\end{array}$} \\
\hline & $n$ & $\%$ & $n$ & $\%$ & \\
\hline Total & 627 & 93.3 & 45 & 6.7 & \\
\hline $\begin{array}{l}\text { Age at transplant } \\
\text { (years) }\end{array}$ & & & & & 0.2368 \\
\hline$<5$ & 553 & 93.7 & 37 & 6.3 & \\
\hline$\geq 5$ & 74 & 90.2 & 8 & 9.8 & \\
\hline
\end{tabular}

PTDM, post-transplant diabetes mellitus.

Table 5. Primary immunosuppression by GI/PTDM status

\begin{tabular}{|c|c|c|c|c|}
\hline Row \% & $\begin{array}{l}\text { GI/PTDM } \\
<30 \\
\text { days } \\
n=166\end{array}$ & $\begin{array}{l}\text { GI/PTDM } \\
>30 \\
\text { days } \\
n=48\end{array}$ & $\begin{array}{l}\text { No } \\
\text { GI/ } \\
\text { PTDM } \\
n=1397\end{array}$ & $\mathrm{p}$-value \\
\hline \multicolumn{5}{|c|}{$\begin{array}{l}\text { Primary immunosuppression } \\
\text { (overall } p<0.0001 \text { ) }\end{array}$} \\
\hline $\operatorname{CsA}(n=433)$ & 5.5 & 1.6 & 92.8 & $<0.0001$ \\
\hline $\mathrm{TAC}(\mathrm{n}=931)$ & 14.2 & 3.9 & 82.0 & Reference \\
\hline $\begin{array}{l}\text { Other/unknown } \\
(n=247)\end{array}$ & 4.0 & 2.0 & 93.9 & $<0.0001$ \\
\hline \multicolumn{5}{|c|}{$\begin{array}{l}\text { Steroids use at Tx } \\
\text { (overall } p=0.0019 \text { ) }\end{array}$} \\
\hline Yes $(n=1459)$ & 11.2 & 3.2 & 85.7 & 0.0019 \\
\hline No $(n=152)$ & 2.0 & 1.3 & 96.7 & Reference \\
\hline \multicolumn{5}{|c|}{$\begin{array}{l}\text { Monoclonal/polyclonal } \\
\text { antibodies } \\
\text { (overall } p=0.5608 \text { ) }\end{array}$} \\
\hline Yes $(n=219)$ & 11.4 & 3.7 & 84.9 & 0.5608 \\
\hline No $(n=1392)$ & 10.1 & 2.9 & 87.0 & Reference \\
\hline
\end{tabular}

Gl, glucose intolerance; PTDM, post-transplant diabetes mellitus; CsA, cyclosporine A: TAC, tacrolimus; $T x$, transplantation.

p-value compares GI/PTDM within first 30 days vs. no Gl/PTDM after first 30 days.

patients were placed on tacrolimus therapy and $26.9 \%$ received cyclosporine. Children placed on tacrolimus therapy have a higher incidence of early GI/PTDM (14.2\%) compared to those taking cyclosporine $(5.5 \%$; p-value $<0.0001)$. More than $90 \%$ of children were initially given steroids. Eleven percent of these children developed early GI/PTDM compared to only $2.0 \%$ of children not using steroids at transplant $(p$-value $=0.0019)$. The use of induction therapy at transplant did not have an impact on the development of GI/PTDM in this analysis.

Factors significant at 0.15 level in the univariate analyses were added to the initial multivariate model to identify risk factor for the development of early GI/PTDM. The final multivariate model presented in Table 7 shows that children $<5 \mathrm{yr}$ of age at transplant, not hospitalized, and diagnosed with BA are protected against the development of early GI/PTDM. 
Table 6. Immunosuppressant levels in patients with and without diabetes

\begin{tabular}{|c|c|c|c|c|}
\hline $\begin{array}{l}\text { Initial immunosuppression } \\
\text { dose levels }\end{array}$ & & $\begin{array}{l}\text { No PTDM } \\
\text { within } 30 \\
\text { days }\end{array}$ & $\begin{array}{l}\text { PTDM } \\
\text { within } \\
30 \text { days }\end{array}$ & $\begin{array}{l}\text { Kruskal-Wallis } \\
\text { p-value }\end{array}$ \\
\hline $\begin{array}{l}\text { Methylprednisoline } \\
(\mathrm{mg} / \mathrm{kg} / \text { day) }\end{array}$ & $\begin{array}{l}\mathrm{n} \\
\text { Mean } \\
\text { s.e. } \\
\text { Median }\end{array}$ & $\begin{array}{r}1265 \\
10.62 \\
0.38 \\
9.71\end{array}$ & $\begin{array}{l}161 \\
11.62 \\
1.16 \\
9.62\end{array}$ & 0.7075 \\
\hline $\begin{array}{l}\text { Hydrocortisone } \\
\text { (mg/kg/day) }\end{array}$ & $\begin{array}{l}\mathrm{n} \\
\text { Mean } \\
\text { s.e. } \\
\text { Median }\end{array}$ & $\begin{array}{l}20 \\
34.79 \\
8.96 \\
15.88\end{array}$ & 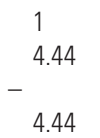 & 0.4090 \\
\hline $\begin{array}{l}\text { Prednisone } \\
\text { (mg/kg/day) }\end{array}$ & $\begin{array}{l}\text { n } \\
\text { Mean } \\
\text { s.e. } \\
\text { Median }\end{array}$ & $\begin{array}{l}699 \\
1.18 \\
0.05 \\
0.91\end{array}$ & $\begin{array}{l}113 \\
0.67 \\
0.05 \\
0.48\end{array}$ & $<0.0001$ \\
\hline Tacrolimus (mg/kg/day) & $\begin{array}{l}\mathrm{n} \\
\text { Mean } \\
\text { s.e. } \\
\text { Median }\end{array}$ & $\begin{array}{r}823 \\
0.16 \\
0.00 \\
0.15\end{array}$ & $\begin{array}{l}141 \\
0.18 \\
0.01 \\
0.14\end{array}$ & 0.8254 \\
\hline $\begin{array}{l}\text { Tacrolimus day } 7 \\
\text { trough level }\end{array}$ & $\begin{array}{l}\mathrm{n} \\
\text { Mean } \\
\text { s.e. } \\
\text { Median }\end{array}$ & $\begin{array}{r}850 \\
12.78 \\
0.23 \\
11.85\end{array}$ & $\begin{array}{r}127 \\
12.87 \\
0.59 \\
11.50\end{array}$ & 0.8618 \\
\hline
\end{tabular}

PTDM, post-transplant diabetes mellitus.

Table 7. Multivariate analysis of risk factors for GI/PTDM within 30 days of transplant

\begin{tabular}{|c|c|c|c|c|c|}
\hline Factor & $\begin{array}{l}\text { Comparison } \\
\text { group }\end{array}$ & $\begin{array}{l}\text { Reference } \\
\text { group }\end{array}$ & $\begin{array}{l}\text { Odds } \\
\text { ratio }\end{array}$ & $95 \% \mathrm{Cl}$ & $p$-value \\
\hline $\begin{array}{l}\text { Immunosuppression } \\
\text { drug } \\
\text { (over all } \\
p<0.0001 \text { ) }\end{array}$ & $\begin{array}{l}\text { CsA } \\
\text { Other/ } \\
\text { unknown }\end{array}$ & TAC & $\begin{array}{l}0.36 \\
0.39\end{array}$ & $\begin{array}{l}0.23-0.57 \\
0.19-0.81\end{array}$ & $\begin{array}{l}<0.0001 \\
0.0116\end{array}$ \\
\hline $\begin{array}{l}\text { Patient status at } \\
\text { transplant } \\
\text { (over all } \\
p<0.0001 \text { ) }\end{array}$ & $\begin{array}{l}\text { ICU } \\
\text { Hospital/ } \\
\text { no ICU }\end{array}$ & $\begin{array}{l}\text { Not } \\
\text { hospitalized }\end{array}$ & $\begin{array}{l}2.63 \\
1.71\end{array}$ & $\begin{array}{l}1.72-4.01 \\
1.04-2.80\end{array}$ & $\begin{array}{l}<0.0001 \\
0.0345\end{array}$ \\
\hline $\begin{array}{l}\text { Age (years) } \\
\text { at transplant } \\
\text { (over all } \\
p=0.0028 \text { ) }\end{array}$ & $\begin{array}{l}{[1,5)} \\
{[5,13)} \\
13+\end{array}$ & $(0,1)$ & $\begin{array}{l}1.02 \\
1.69 \\
2.38\end{array}$ & $\begin{array}{l}0.63-1.65 \\
1.01-2.84 \\
1.39-4.06\end{array}$ & $\begin{array}{l}0.9381 \\
0.0475 \\
0.0015\end{array}$ \\
\hline $\begin{array}{l}\text { Steroid use at } \\
\text { transplant }\end{array}$ & Yes & No & 3.67 & $1.05-12.85$ & 0.0421 \\
\hline $\begin{array}{l}\text { Primary disease } \\
\text { (over all } \\
\quad p=0.0522 \text { ) }\end{array}$ & $\begin{array}{l}\text { Other } \\
\text { cholestatic } \\
\text { Metabolic } \\
\text { Fulminant } \\
\text { Cirrhosis } \\
\text { Other }\end{array}$ & $\begin{array}{l}\text { Billiary } \\
\text { atresia }\end{array}$ & $\begin{array}{l}1.74 \\
1.53 \\
0.72 \\
1.34 \\
1.27\end{array}$ & $\begin{array}{l}1.04-2.92 \\
0.89-2.65 \\
0.38-1.36 \\
0.70-2.57 \\
0.68-2.37\end{array}$ & $\begin{array}{l}0.0367 \\
0.1280 \\
0.3124 \\
0.3801 \\
0.4620\end{array}$ \\
\hline
\end{tabular}

Gl, glucose intolerance; PTDM, post-transplant diabetes mellitus; CsA, cyclosporine A; TAC, tacrolimus; ICU, intensive care unit.

\section{Discussion}

In this study, we found that GI/PTDM occurred in approximately $13 \%$ of patients who received a liver transplant. This incidence was similar to the incidence of PTDM in other solid organ transplants in children (5). More than three-quarters of the children developed GI/PTDM within one month of transplant, but the mean duration of GI/PTDM in this cohort was relatively short 74 days suggesting that diabetes in this analysis is a transient phenomenon. Only a few children developed GI/PTDM at one or $>1 \mathrm{yr}$ after transplant, but the reported duration was longer. The results of the multivariate analysis showed that early GI/PTDM in pediatric liver transplant recipients is associated with older age, diagnosis other than BA, and the use of tacrolimus and steroids.

The diabetogenic effect of several commonly used immunosuppressive drugs is well known and our results support several other reports including those in which steroids and/or tacrolimus were used as primary immune suppressants (4-6). In our study, steroid predominance at the outset, and tacrolimus use in the majority, might have contributed to the observed incidence of GI/PTDM. The odds ratios for both these therapies suggest a similar strength of association with PTDM. This contrasts with a much lesser frequency of PTDM in heart transplant recipients when placed on a steroid-sparing cyclosporinebased regimen (11). Dose effects, particularly cumulative steroid exposure, could not be analyzed within the context of this study, but are important aspects to consider in future prospective analyses. Separating the independent role of steroids in the development of GI/PTDM is an important objective as new treatment initiatives in pediatric transplantation suggest that steroidfree regimens do not compromise graft function or survival.

The significant association of both tacrolimus and steroids with early GI/PTDM support two important clinical strategies. First, reducing corticosteroid exposure could decrease, but probably not eliminate PTDM in this population. Secondly, in children who develop GI/PTDM, consideration should be given to decreasing or stopping steroids. If hyperglycemia is difficult to control with standard insulin dosages, substituting cyclosporine, mycophenolate mofetil, or sirolimus should be considered if graft function is stable.

The other significant risk factors for early GI/ PTDM identified in multivariate analysis were recipient age $>5 \mathrm{yr}$ and a primary diagnosis other than BA. A protective effect of BA, independent of age and BMI at transplant is not easily explained, and may just be a random association or be related to other patient covariates. The incidence of diabetes in children with BA who did not receive a liver transplant is not clearly identified in the current literature. As the pathogenesis of BA is still 
unknown, the importance of the association we have shown remains to be elucidated. Protection against diabetes in patients with $\mathrm{BA}$ may be related to disease-specific diabetes resistant HLA subtypes and cytokine gene polymorphisms (12). The independent effect of age $>5 \mathrm{yr}$ may be related to the known increased incidence of insulin-resistant (type 2) diabetes with age in all children. High BMI is a well-described risk factor for the development of this type of diabetes in children (13). The lack of correlation with BMI in this study is likely because we only assessed BMI at transplant as a risk factor for developing early GI/ PTDM. Future longitudinal studies are needed to understand the effect of BMI on the development of PTDM during long-term follow up.

An inherent caveat to this analysis, is the discrepancy between the definition of diabetes in the SPLIT database at the time of the study, and the standard definition by the ADA (14). Although the latter definition of a fasting blood glucose in excess of $124 \mathrm{mg} / \mathrm{dL}$ or a post-prandial level exceeding $200 \mathrm{mg} / \mathrm{dL}$ may not have been consistently used by participating centers, children were primarily classified as diabetic based on their need for insulin or other antihyperglycemic drugs. It is assumed that most clinicians considered this definition in their decision to initiate insulin or other anti-hyperglycemic therapy. The definition of diabetes used for this study likely excluded children with undiagnosed or untreated diabetes and those who would be considered prediabetic and thus underestimated true incidence. Screening for PTDM has become more rigorous at pediatric transplant centers within the recent past and the current follow-up data collection for the SPLIT registry includes fasting glucose values on all children age five $y r$ and older. This more careful investigation may reveal an even larger population of children that are classified as diabetic using the ADA definition.

Another limitation of this analysis is that it is based on a large multi-center database in which long-term follow-up data may not be available, or consistently collected on patients from various centers. Long-term follow-up regarding compliance with the immunosuppressive regimen and annual blood glucose testing may similarly be incomplete, compromising the accuracy of the above results. These effects would be expected to further contribute to an underestimation of the true incidence. Patients with no follow-up may have diabetes which does not come to medical attention, and patients that die early in their post-transplant course may have developed diabetes with prolonged exposure to immunosuppressive medications. A comprehensive, prospective screening program that incorporates ADA guidelines and definitions will be necessary to more confidently estimate the risk of PTDM.

The mechanism of pediatric post-transplant diabetes is likely to be a composite scenario of both insulin deficiency and insulin resistance. This pertains to both conventional steroid-based regimens, as well as more experimental steroidfree protocols that may include other immunosuppressants, such as sirolimus, polyclonal, or monoclonal antibody preparations. Steroids are known antagonists of insulin action (11). Sirolimus has opposing effects on islet function dependent on the dose (15). The mechanism by which tacrolimus may lead to diabetes is a complex one, where islet cell-specific autoimmunity, insulinopenia and insulin resistance have been suggested (16). We do not know, if the known diabetogenic effects of calcineurin inhibitors and steroids are independent, additive, or synergistic. Considering that immune suppression in this vulnerable (pediatric) age group may span several decades, there is concern over chronic effects on micro- and macrovascular systems that warrants more comprehensive short- and long-term monitoring.

To further understand the pathogenesis of posttransplant diabetes (17), future studies should include testing for endogenous insulin production and insulin resistance by measuring plasma glucose and C-peptide (the connecting peptide of the two endogenous insulin chains). In this study, the pathogenesis of PTDM is limited by the lack of comprehensive pretransplant glucose tolerance evaluation, especially as insulin-resistant diabetes is asymptomatic in approximately $50 \%$ of patients (18). Improved pretransplant screening for GI is indicated. Glycemic, autoimmune, and HLA characteristics of children and adolescents developing PTDM and determinants of oral antihyperglycemic drugs vs. insulin therapy remain to be described prospectively. A better understanding of the pathogenesis of PTDM may allow for the development of a predictive index for pediatric PTDM which could have a pivotal impact on immune suppression selection. This, in turn, may highly enhance the duration and quality of life in liver transplant recipient children.

\section{Acknowledgments}

SPLIT is funded by National Institutes of Health (NIDDK Co-op U01 DK0616693-01A1) with additional funding from Astellas Pharma US, Inc. 


\section{References}

1. Nieuwenhuis MG, Kirkels JH. Predictability and other aspects of post-transplant diabetes mellitus in heart transplant recipients. J Heart Lung Transplant 2001: 20: 703-708.

2. First MR, Gerber DA, Hariharan S, et al. Posttransplant diabetes mellitus in kidney allograft recipients: Incidence, risk factors, and management. Transplantation 2002: 73: 379-386.

3. Greenspan LC, Gitelman SE, Leung MA, et al. Increased incidence in post-transplant diabetes mellitus in children: A case-control analysis. Pediatr Nephrol 2002: 17: 1-5.

4. Al-Uzri A, Stablein DM, A Cohn R. Posttransplant diabetes mellitus in pediatric renal transplant recipients: A report of the North American Pediatric Renal Transplant Cooperative Study (NAPRTCS). Transplantation 2001: 72: 1020-1024.

5. Paolillo JA, Boyle GJ, Law YM, et al. Posttransplant diabetes mellitus in pediatric thoracic organ recipients receiving tacrolimus-based immunosuppression. Transplantation 2001: 71: 252-256.

6. Shapiro R, Scantlebury V, Jordan ML, et al. Posttransplant diabetes in pediatric recipients on tacrolimus. Transplantation 1999: 67: 771 .

7. Hathaway DK, Tolley EA, Blateely ML, et al. Development of an index to predict posttransplant diabetes mellitus. Clin Transplant 1993: 7: 330-338.

8. Miles AM, Sumrani N, Horowitz R, et al. Diabetes mellitus after renal transplantation: As deleterious as non-transplantassociated diabetes? Transplantation 1998: 65: 380-384.

9. Boudreaux JP, McHugh L, Canafax DM, et al. The impact of cyclosporine and combination immunosuppression on the incidence of posttransplant diabetes in renal allograft recipients. Transplantation 1987: 44: 376-381.

10. McDiarmid SV, Anand R, and the SPLiT Research Group. Studies of Pediatric Liver Transplantation (SPLIT): A summary of the 2003 Annual Report. Clin Transpl 2003: 119-130.

11. Hathout EH, Chinnock RE, Johnston J, et al. Pediatric post-transplant diabetes. Data from a large cohort of pediatric heart transplant recipients. Am J Transplant 2003: 3: 994-998.

12. Donaldson PT, Clare M, Constantini PK, et al. HLA and cytokine gene polymorphisms in biliary atresia. Liver 2002: 22: 213-219.

13. Girardin CM, Schwitzgebel VM. Diabetes type 2 in pediatrics: Diagnosis and management. Rev Med Suisse 2007: 3: 1001-1005.
14. American Diabetes Association. Standards of medical care in diabetes - 2006. Diabetes Care 2006: 29(Suppl. 1): S4-S42.

15. Shapiro AmJ, Gallant HL, Hao EG, et al. The portal immunosuppressive storm. Relevance to islet transplantation? Ther Drug Monit 2005: 27: 35-37.

16. Yoshioka K, Sato T, Okada N, et al. Post-transplant diabetes with anti-glutamic acid decarboxylase antibody during tacrolimus therapy. Diabetes Res Clin Pract 1998: 42: 85-89.

17. Midtvedt K, Hartmann A, Huefmesaeth J, et al. Insulin resistance is a common denominator of post-transplant diabetes mellitus and impaired glucose tolerance in renal transplant recipients. Nephrol Dial Transplant 1998: 13: 427-431.

18. Scognamiglio R, Negut C, Ramondo A, Tiengo A, AvoGARO A. Detection of coronary artery disease in asymptomatic patients with type 2 diabetes mellitus. J Am Coll Cardiol 2006: 47: $65-71$.

\section{Appendix}

\section{Participating SPLIT centers}

Alfred I. DuPont Hospital for Children; Boston Children's Hospital; Cardinal Glennon Children's Hospital; Children's Healthcare of Atlanta; Children's Hospital of Denver; Children's Hospital of Philadelphia; Children's Hospital of Pittsburgh; Children's Hospital of Western Ontario; Children's Hospital of Cincinnati; Children's Hospital of Wisconsin; Children's Medical Center of Dallas; Children's Memorial Medical Center, Chicago; Children's Mercy at Kansas City; Hospital for Sick Children, Toronto; Indiana University Medical Center; Johns Hopkins University; LeBonheur Children's Medical Center; Mayo Medical School; Medical College of Virginia; Medical University of South Carolina; Mount Sinai Medical Center; New York Presbyterian Hospital; Primary Children's Medical Center, Utah; Sainte-Justine Montreal; Stanford University; St Christopher's; St Louis Children's Hospital; Texas Children's Hospital; UC Los Angeles; UC San Diego; UC San Francisco; University of Alberta, Edmonton; University of Chicago; University of Florida, Shands; University of Miami/Jackson Memorial Hospital; University of Michigan; University of Minnesota; University of Nebraska; University of North Carolina, Chapel Hill; University of Rochester; University of Texas HSC, San Antonio; University of Washington, Seattle; University of Wisconsin. 